\title{
A Critique of Educational Research
}

\section{PÁDRAIG HOGAN}

In an article entitled 'The psychologist's contribution to educational research' [I] Professors J. D. Nisbet \& N. J. Entwistle begin by surveying briefly different definitions of educational research itself with a view to drawing a distinction between "pure research in the social sciences and educational research in the area of the applied sciences" [2]. Having suggested this distinction the authors clearly favour a definition which would remove educational research from the category of pure to that of applied research and, accordingly, their own definition states that "educational research consists in careful, systematic attempts to understand the educational process and, through understanding, to improve its efficiency" [3]. Pursuing the consequences for educational enquiry of the definition they themselves outline, Nisbet $\&$ Entwistle point out that

this shift in emphasis from 'understanding' to 'improvement' is likely to be disputed by many who are active in what they claim to be wholly respectable educational research which does not aim at 'improvement'-such as historical studies and comparative education. [4]

Although allowing that a broader definition must be accepted for those educational studies which 'do not aim at improvement' the professors emphasise that educational research which seeks to influence the conduct of events must be envisaged "in practical terms, with reference to conditions as they are" [5]. Not surprisingly the behavioural sciences, particularly psychology and sociology, gain an easy ascendancy in this scheme but, more particularly, empirical studies in psychology and sociology are now awarded pride of place in educational research.

The significance of the above-mentioned article-apart from any initial significance conferred by the distinguished reputation of its authors-rests in its forthrightness on a number of issues which usually remain untackled or only lightly touched upon in the literature of education [6]. First, in its opening sentences it draws a clear and deliberate distinction between, on the one hand, 'pure' or basic educational research and, on the other, 'practical' or applied research. Secondly, this distinction is made more complete by describing applied research in education in terms of empirical studies in psychology and sociology, as distinct from more inclusive conceptions of psychology and sociology. Thirdly, Nisbet \& Entwistle, in arguing a case for the more restricted definition, make the important claim that 'a definition which includes the notion of 'improvement' is increasingly being applied in deciding priorities in educational research" [7].

These points, and particularly the third one, have a decisive importance, as the appropriateness of the critique about to be attempted here depends largely on the extent to which Nisbet \& Entwistle's claim is an accurate one, for if it is not accurate to any widespread degree then the critique itself would, in that degree, be unnecessary. Pursuing this a little further it is important to state clearly at the outset that the object of the critique is not just the stated position of Nisbet \& Entwistle; neither is it in any accurate sense a questioning of the right to a central place in educational research of the disciplines of 


\section{Oxford Review of Education}

psychology or sociology. Rather its object is the growing tendency at an international level to conceive of educational research itself in terms of the 'narrower definition', the essential features of which have been clearly described by Nisbet \& Entwistle.

What must be assessed then before the critique can get under way is the extent to which the 'growing tendency' mentioned above is just that; or, in other words, the extent to which educational research has become primarily an empirical investigation of aspects of the learning process within the context of 'conditions as they are'. To establish conclusively that this is the way educational research has developed and continues to develop would require nothing less than a detailed global survey of the recently completed work and the projects in hand of all institutions where educational research is seriously undertaken and of the organisations under whose auspices it is undertaken. This would be a well nigh endless task, even for a team of investigators, so instead of attempting to establish anything in this way it might be more fruitful to concentrate on a few points which evidence the growth to prominence of empirical studies in educational research.

Firstly, the funding of educational research studies is predominantly in favour of empirical projects which aim at investigating and improving aspects of a particular educational system, along the lines detailed by Nisbet \& Entwistle. Indeed in the political climates of most western countries, public monies spent on non-empirical educational research would perhaps most likely be seen, from the point of view of funding agencies, much in the same category as money spent on 'the arts' (i.e. not a priority area for resource allocation). Secondly, the training of educational research workers tends to emphasise the importance of developing the skills of statistical measurement, data analysis, questionnaire design and of developing also a fluency in the language and concepts of the behavioural sciences, particularly terms which can be given operational definition [8]. Thirdly, a survey of any issue of published abstracts of dissertations presented for higher degrees in North America and Europe indicates that the great majority of studies undertaken are empirical in nature [9]. Fourthly, in the large American publication Encyclopaedia of Educational Research two articles deal with the topic of educational research itself. The text of these presuppose that educational enquiry is almost exclusively an empirical-scientific pursuit, despite the remark in the editors' preface that they view educational research in a much broader way [10]. Finally, the style of educational writing in recent years has changed gradually, but dramatically. The number of books on education has increased rapidly and has largely become the province of technical experts. This trend is considered in some detail by W. Kenneth Richmond in his critical survey of the literature of education. He concludes that with the arrival of the technical expert in the field of educational research "it is as though there is no longer any place (in the literature) for human warmth, only for clinical concepts, desiccated statistics and aseptic analysis" [II].

Taken together, these five points suggest that the predominant outlook in educational research at present is one which shifts the methodological perspective of that research itself ever more in the direction of a scientific empiricism. The progressive ascendancy of this perspective bears witness to the extent to which educational research itself is becoming identified with the 'narrower definition' described above and for this reason calls for a searching investigation not only into the current position but also into the nature of educational research itself. A preliminary attempt in this direction follows here.

\section{THE DECISIVE IMPORTANCE OF PRESUPPOSITIONS IN METHODICAL ENQUIRY}

One might begin by examining some of the unstated assumptions of the more prevalent 
concept of educational research just outlined and then proceed to consider their consequences with a view to establishing the extent to which an appropriate and adequate foundation for research has been established. First, then, there is in this concept a strong assumption that historical, comparative or philosophical studies do not have a direct relevance, or are of secondary importance, to any educational research which might include in its purposes a practical concern for improvements in the conduct of formal education. Secondly, the nature of the shift in emphasis from 'understanding' to 'improvement', from the learning process itself to 'conditions as they are' assumes an existing educational system, rather than education per se, as the context of enquiry. Consequently, it will be argued, the term 'understanding' loses its vital significance for research and, in a subtle but decisive way, becomes itself effectively redefined as: understanding the particulars of an existing educational system. Thirdly, and most importantly, the extent to which educational research simply, or merely, adopts the 'empirical' procedures of the social sciences, particularly 'empirical' psychology and 'empirical' sociology, marks the extent of its dependence on the methodology of the natural sciences, on which all 'empirical' enquiry is based. The critique will propose that an automatic or uncritical adoption of these methods overlooks the question of the nature of the process, object, or being to be examined, i.e. whether it is properly to be conceived of as organic, inorganic or human.

Turning now to consider each of these assumptions, let us start by examining the consequence of the first one, namely the effective relegation of non-empirical studies, particularly those of a historical, comparative or philosophical nature, to a position of secondary importance in any research concerned with practical educational improvement. Do the reasons which might explain this relegation also provide its justification? These reasons themselves must rest on an assumption that comparative, historical and philosophical studies are concerned essentially with something other than the 'real world' where practical education takes place, although it usually remains unclear what precisely this kind of assumption regards the proper domain of non-empirical enquiry to be. When serious attention is given to this question however-that of the proper domain of nonempirical studies-it becomes clear that, in a more radical sense than with empirical studies, they provide fertile grounds upon which far-reaching educational improvements can be based. Historical, philosophical and comparative studies can bring to light and articulate ideas, insights and aspirations which transcend those of the established educational practice and provide a fruitful source of arguments for the qualitative improvement or transformation of that practice at its most formal and informal levels.

The following illustration should help to clarify this point. The notions of Permanent Education and Recurrent Education which have recently become central in educational discourse nationally and internationally, are based on a distinctly philosophical argument. This argument holds that education is inadequately conceived unless it is, from the start, placed firmly in the context of one's unfolding experience over the entire span of one's lifetime [12]. Existing educational provision on the other hand, rests, for the most part, on the belief that the years of one's childhood and youth are the years of one's education, and in this way education is usually seen and conducted as a preparation for life in society which is completed in one's youth. Historical studies show that this identification of education with the widespread completion of training and preparation is a development of the late eighteenth and nineteenth centuries which can broadly be linked to the consequencies of unprecedented industrialisation and urbanisation [13]. Historical studies of educational ideas and of educational institutions show further that older notions of education were quite distinct from the notion of a widespread completion of preparation and training in youth and were concerned rather with the development of the intellectual 


\section{Oxford Review of Education}

capacities of a minority, often with a view to continuing involvement with scholarship of various kinds during the course of one's lifetime [I4]. Comparative studies of education in different societies offer further perspectives on, and help further to bring to fullness, the notions of Permanent Education and Recurrent Education. For instance, a study of the educational systems of eastern countries [15], or 'Third World' countries [16], shows that Permanent Education is a notion which has grown up out of the western tradition of education, that its challenge is indeed a most radical one for educational improvement and is directed specifically at the roots of the conventional pattern of education in western countries. Other examples could also be drawn upon to show that, in a primary sense, studies of a non-empirical nature, more so than empirical studies, can articulate the kind of thinking which gives to practical educational discourse its essential vitality, and to suggestions for educational improvement a more fundamental sense of context and direction.

Challenges of the nature just outlined are however likely to remain overlooked by an empirical research which considers as its primary concern that of understanding the particulars of a given educational system with a view to improving that system's efficiency. This restriction in the scope of enquiry and understanding which the second assumption brings about means that educational research, in the narrower definition, engages itself primarily with questions defined by the rationale of an existing educational system and of its quantitative extension rather than with questions of its qualitative improvement or transformation. This is not to suggest that the application of the fruits of empirical studies does not supply more efficient and more humane means of reaching and of extending the goals of any particular educational system, but it is to argue that such application leaves these goals largely unquestioned and the character of the system itself largely unaltered. Critically viewed, moreover, the restriction of scientific purpose in educational research to an examination of 'conditions as they are' or, more formally, to an investigation of the particulars of a given educational system, contains an anomaly, particularly if the investigation explicitly claims to be scientific and lays claim to the title 'educational research'. Again, an example might serve to illustrate this anomaly.

A genuinely scientific impulse arises from an unconditional desire to understand (otherwise it is pseudo-scientific) and it therefore seeks to get to the very heart of its object of enquiry. Wherever the method adopted to facilitate this enquiry attains the character of an unquestioned methodology, or more precisely 'method-ideology', the enquiry is no longer unconditional but its own understanding is rather conditioned by the operations permitted by the methodology. When this happens in any scientific discipline investigations may continue to occur, but the status of the discipline itself-its claim to further the search for truth-is unlikely to be advanced unless and until the methodology is broken asunder and re-established on a different basis. Scientific positivism in the nineteenth century, for instance, insisted that observable phenomena and positive facts were the only legitimate material for scientific investigation. The development of 'molecular', and later 'quantum' physics, which began by the positing of hypothetical, as distinct from observable 'molecules', had first to reject the methodology of scientific positivism and only out of this rejection could physics advance to show that there was infinitely more to the natural order than could be observed, even through a microscope. Similarly, philosophical positivism in the first part of the twentieth century insisted that the only legitimate objects for philosophical enquiry were, first, formal propositions of undisputed fact, i.e. tautological propositions merely elaborating the logical properties of definitions and, secondly, propositions which could either be finally verified or finally rejected by empirical observation. This philosophical approach ruled out from enquiry the entire field of human experience as it unfolds in, and is experienced by individuals. The methodo- 
logical implications of this can be seen in Behaviourism, which takes as its datum aspects of the exhibited behaviour of humans rather than the world of experience which underlies that behaviour.

Bringing these points to bear on the assumption under consideration, one can appraise more clearly a definition of educational research which understands itself primarily in terms of investigations of the exhibited behaviours and features of a particular educational system, and, accordingly, which removes to the background investigations which seek to bring more dimensions of the system to light in a more inclusive context. It now becomes clear that such a definition, notwithstanding its fruits, has not escaped the behaviourist legacy of positivism. In so far as it fails to establish self-critically from the start an adequate conception of the field to be studied, namely education per se, empirical educational research loses sight of the necessity for understanding to be unconditional in its aim and accordingly it must suspend its claim to be a genuinely scientific endeavour. The consequence of this loss moreover, namely the removal of non-empirical educational studies to a secondary position, betrays the influence of the 'ruling out' operations of positivism and reveals more clearly the questionable nature of the claim to scientific status.

The third assumption, which uncritically adopts the methods of the natural sciences for the study of education, is closely related to the second, which, it was argued, leads to an inadequate grasp of the field to be studied. In considering this third assumption our attention will be more closely focused on the methodological issues touched upon above and will be particularly concerned with the question of the appropriateness of the methods of the natural sciences to the task of bringing a satisfactory understanding of education within our grasp. The methods of the natural sciences presuppose a decisive distinction, indeed a dichotomy, between the scientist and the objects of scientific investigation. Much of the fruitfulness of scientific research can be attributed to the very decisiveness with which the dichotomy is established and the rigour with which it is maintained. The scientist is conceived of here as a detached objective mind, observing, classifying and noting accurately the characteristics and behaviours exhibited by the entity or process under investigation. On the basis of data gathered in this way significant issues are brought to the fore, hypotheses are formulated, and are verified, rejected or reformulated as they are tested and monitored by further objective scrutiny. In all of this procedure, described as 'empirical verification', careful attention is given to preserving the objectivity of the scientist: his detachment and differentiation in status from the material under investigation. The scientist has the methodological status of 'observer' while his object has the status of being 'observed'. Without detracting in any way from the fruits of these investigations-namely, the products of inventions, discoveries and technological developments which are taken for granted in our everyday lives-it remains open to question whether these methodical procedures are the exclusive means by which the natural order in its fullness can be understood. What is decidedly more questionable however, and what concerns us directly here, is whether the methodology of the natural sciences, or any adaptation of it, can in any but the most tentative or provisional sense be applied to the human order of experience, as distinct from the world of nature investigated by the physical and biological sciences.

When the object of investigation is nothing other than ourselves, our social relationships and the institutions we create arising out of these relationships, is there not a fundamental anomaly in maintaining here a methodological formula of 'observer' and 'observed', together with the dichotomy it imposes? The demands inherent in this formula call always for the elimination of any trace of 'subjective bias'. Consequently, only the behavioural surface of human experience can be objectively disclosed, as the world of experience itself which underlies this surface is radically subjective in its nature and can 
never be disclosed with the kind of objectivity demanded by the natural sciences. For instance, a purely objective study - say a carefully designed questionnaire-can perhaps show a significant correlation between pupils' academic performance in school and such things as the values of pupils' parents, families and peer groups, observed levels of 'introversion', 'extraversion' or 'deviance' in pupils, mixed or single sex classrooms. Such a study cannot, however, disclose the more vital character, flavour or atmosphere of peer group, home life or classroom, or trace the vital connection between, on the one hand, what is observed as 'introversion', 'extraversion' or 'deviance' and, on the other, the context of experience where these arise.

Inorganic properties and processes can be said to behave in certain ways. The same can be said of plants, animals and other organic entities. It is doubtful however if any of these can properly be said to experience. Even if it were granted that a sense of experience of some kind could be attributed to them it would be very different from the type of experience we know, and have historically known, as human. Hence a methodology designed to discover the behaviours of entities and processes in an objective and conclusive manner cannot simply be employed in a field whose unique characteristic is self-conscious human experience, which is both personal and interpersonal in nature. An uncritical adoption by social or human sciences of the methodology of the natural sciences sometimes may (and indeed does) produce creditable results. Such results are most likely to occur when regularities in observed characteristics and behaviours (as witnessed by significant degrees of correlation) bear a direct relation to the experiences which account for them. Where such regularities are not present, however; where exhibited behaviour serves only as an indirect, enigmatic or even misleading clue to the experiences which underlie it-and this may often be the case with people's deeper feelings, particularly when subjected to formal questioning - then the inadequacies and the methodological inappropriateness of empirical methods of investigation become apparent, whenever they claim a primacy or exclusiveness in disclosing the characteristic features of the more important aspects of human thought, discourse and action. Hence the need for empirical educational research to acknowledge the tentative status of its findings can now be seen as a methodological necessity. The extent to which research fails to carry out this acknowledgement and asserts instead a claim to primacy or exclusiveness measures the extent of its own shortcomings as a scientific endeavour.

This investigation of some of the presuppositions of empirical enquiry in the social sciences enables us to recognise now that the question of what it means to educate, or to become educated, calls not merely for an analysis of conditions as they are in any particular educational system-whether or not carried out by the empirical methods of the natural sciences-but calls more fundamentally for a method which facilitates its proper unfolding as a question worthy of the most rigorous and painstaking research. In the second part of this essay an attempt will be made to give an outline of such a method and in this way will seek to articulate a context which brings some conception of the fullness of human understanding satisfactorily within our grasp. The possession of such an understanding should then help us to approach the question of education in a truly original manner and should also help us to say something positive about the relation between different kinds of research in education.

\section{THE INTERPRETATIVE-HISTORICAL STRUCTURE OF UNDERSTAND- ING}

Our understanding of ourselves, of the social world in which we live and of worlds of experience or traditions different from our own, is never free from presuppositions. 
Indeed, it is an accumulation of previous understandings, which have become significant to us in one way or another, which enables us to understand anything new. But in enabling us to understand something new our previous experience of understanding influences the manner in which that new understanding takes place. In other words, human understanding is quite erroneously thought of when it is characterised as a presuppositionless acquisition of knowledge. This is to argue that understanding is never merely cognitive but is always an interpretative act in which one's previous experiences play a central part. For instance, agreeable or disagreeable, easy or difficult experiences of mathematics, a foreign language, or of schooling more generally will play a vital part in how a pupil will come to view further encounters in these fields. It might be objected here that, while this may be the case with understanding a field of study or experience of which one has already had some experiences, the interpretative characterisation of understanding breaks down when one raises the question of introductory experience in any field, or, in other words, the question of how understanding of something of which one has had no previous experience comes about in the first place.

An examination of the question raised in this objection is called for here as its resolution has decisive consequences for the context in which research of any kind is carried out. This is, indeed, a major question which occupied the energies of the most important thinkers in the history of western philosophy since Plato suggested in his Meno that the human capacity to understand, or to acquire knowledge, arose from the pre-existent structure of the soul, which enabled it to collect, or more precisely recollect, its unfolding experiences into the context of its former, more ideal prehuman existence [17]. Although many later philosophers found Plato's argument on this issue unacceptable, the notion of human understanding as something having an a priori or pre-experiential structure, rather than a haphazard or accidental character, prevailed and found perhaps its next most radical expression in the writings of Kant. Kant argued that 'understanding' is the "faculty of cognition through concepts" [18]. These concepts in turn he divided into two kinds: first, a posteriori concepts, namely those abstracted from sense perceptions and, secondly, a priori concepts, which, in being prior to experience, enable us to order or arrange sense perceptions and the concepts abstracted from them in certain ways. One of Kant's most decisive contributions to philosophy was his thesis that the notions of space and time were $a$ priori rather than a posteriori in nature [19]. In other words, he argued that space and time-notions which pervade every moment of our daily experience-are not abstracted from that experience as it unfolds, but are already presupposed or 'taken for granted' and that it is this very pre-supposition or 'taken for grantedness', of which one may scarcely be conscious, which enables one's experience to unfold as it does, i.e. as something having an intelligible character.

Kant then proceeded to show that 'Ideas' of pure reason, namely general notions which do not correspond to anything which can in its fullness be humanly experienced (e.g. freedom, immortality, soul, God),

may yet, in a fundamental and unobserved fashion, be of service to the understanding as a canon for its extended and consistent employment...... (that is) an indispensibly necessary regulative employment, namely, that of directing the understanding towards a certain goal upon which the routes marked out by its rules converge. [20]

Hence, when guided by pure reason, the understanding, Kant points out, is informed by and directed towards ideal standards, which in themselves cannot be attained, but without which, purposeful human discourse would lack any fundamental coherence. Hence Kant's investigations of the conditions which made understanding in its various modes 
possible showed convincingly that understanding was itself structured in particular ways prior to experience and that $i$ was this very structure which made what we recognise as experience possible.

The researches of Heidegger have given a new and decisive impetus to this question. Rather than considering understanding as a "faculty of cognition through concepts" as Kant had done, Heidegger argues that understanding is itself a basic mode of man's presence in a world [2I]. Thus, whereas a 'faculty' has the character of something we may or may not wish to employ, a basic mode of being is something prior to all faculties which constitutes us as human and from which we cannot get away, even if we want to. Understanding, in this sense, also includes mis-understanding, attempted understanding and incomplete or privative understanding. What is understood when understanding takes place (i.e. the contents of understanding) also becomes a focal point of Heidegger's investigation. In traditional philosophical discourse this was called the 'object of knowledge or 'of consciousness', but all such designations, Heidegger argues, were based on a serious oversight. In holding an essentially cognitive and substantive view of understanding, traditional epistemologies did not do justice to the complexities of what is understood and also overlooked the social nature of the world in which understanding takes place. In other words, the problem of understanding was traditionally viewed as one of a relation between a 'conscious knowing' entity and an entity to be 'known'. The procedure of distinguishing the knowing entity by adding to it cognitive, intellectual or spiritual 'attributes' was rarely systematically carried out on the 'known'-which thus remained undistinguished, but in any case such a distinguishing procedure does not alter the fact that the knowing entity was fundamentally characterised as a thinking 'substance' or thing: a res cogitans [22]. Where being human was characterised in this abstract way the crucial importance of its social nature was invariably overlooked. Indeed it is difficult to see how a social dimension could be accommodated in any significant sense in a metaphysics whose language was that of substance categories.

What these metaphysical accounts overlooked, namely the 'contents' of understanding and the social context of the person who understands, are precisely what give to the interpretative characterisation of understanding its decisive thrust. Again, Heidegger points out that the structure of understanding is such, that, whenever we understand something, we simultaneously interpret it as something of a particular sort rather than as an undistinguished 'object of understanding' [23]. We understand other people as people or, more importantly, as friends, as neighbours, as enemies, as fellow citizens, as foreigners. We could also understand them more formally as corporeal entities to which distinguishing attributes are then added. We understand music as classical, as traditional, as popular. We could also understand music as 'sound' to which distinguishing tonal and melodic patterns are then added. We understand tools as hammers, saws, spanners, etc. but we could also understand them as metallic matter forged or moulded to particular shapes and strengths. That which we fail to understand we understand as puzzling or incomprehensible. All of this is stated not to stress what is already obvious, but rather to underline the point that every act of understanding is also an act of informal or formal interpretation whether consciously or unconsciously; otherwise it is not an act of understanding at all.

Proceeding now from the complex nature of what is understood to an examination of the social context in which understanding takes place, it is necessary to point out, first, that this context is not merely a social one but is more precisely a historical-social one. Long before we ever begin any self-examination we understand ourselves in a selfevident way in the family and society in which we grow up. The very self-evidence or naturalness of this kind of understanding may cause us to overlook its historical nature. The context where this kind of understanding takes place is one where certain beliefs, 
attitudes and modes of behaviour are valued and others are discouraged. What is valued or discouraged in this way is rarely an arbitrary decision of any individual but more normally arises from tradition. Tradition and established practice largely determine the character of the social world in which we grow up and, although it is amply possible to take issue with tradition, to criticise its perceived narrowness or prejudices on any number of points, it is not possible effectively to abandon or overthrow it on any wide scale, as the history of revolutions and revolutionary movements has shown [24]. Neither is it possible for any individual to declare that tradition will no longer have a place in his or her life. Where this is attempted, what invariably happens is that one attempts to abandon one tradition only to find oneself involved in another tradition, or in other traditions.

In understanding anything then, we stand always within a tradition and in this way tradition itself structures our understanding; it always exerts a subtle, but decisive influence on the manner in which we understand. This influence, Hans-Georg Gadamer has recently described as the principle of 'effective history' [25], i.e. in understanding anything we are always subject to the effects of our own history on our interpretations. Thus whenever we design a method of enquiry with a view to letting the facts of what we observe 'speak for themselves' in an objective way, we miss an essential dimension of what we are investigating if we take what is thus revealed-an immediate appearance-as the whole truth. The validity of what is revealed always depends on the validity of the question asked, so unless the method in question self-critically examines its questions in the context of its own effective history or, in other words, examines the kind of presuppositions considered in the previous section of this essay, it operates on questionable foundations.

It should not be concluded from these remarks however that in understanding or interpreting anything we are entirely at the mercy of tradition, or that an examination of the presuppositions would merely reveal that what we are to investigate is already predetermined in its outcome by the effects of history on our understanding. The interpretative characterisation of understanding shows that this is precisely not the case wherever a truly alert historical consciousness is brought into play. For just as our previous, or historical context of experience influences the manner in which we interpret particulars, the particulars we interpret also modify the context of our experience, and can do so in a beneficial way which corrects the prejudices and assumptions which we initially bring to the particular question or issue we are attempting to understand. This event recalls to mind an ancient rule of hermeneutics (i.e. the art of textual interpretation), that the whole must be understood in terms of its details and the details in terms of the whole [26]. This old hermeneutic principle can be seen from the above arguments to play a central part in the interpretative characterisation of understanding which has been outlined. The structure of understanding and interpretation can thus be seen to be circular rather than simply linear in nature. An example illustrates this: my previous experiences in a given field provide me with some context or 'whole' (albeit an inadequate or prejudicial one) which enables me to anticipate in certain meaningful ways the particular issues and questions I encounter in this field. My understanding of the particular issues or questions is advanced in the encounter and as a result I also get a clearer, and more advanced notion of the context itself. This clearer notion can now serve as a more adequate starting point for my next encounter with further particular questions in this field [27]. Clearly, this process can also operate conversely. For instance, initial prejudices or assumptions can be confirmed and strengthened rather than overcome as one's experience unfolds.

What we have argued in this section concerning the nature of human understanding should now help us to articulate a context of enquiry where the question of education can 
in its fullness be brought to light and where scholarly attempts to understand the manifold aspects of this question can find a secure and satisfactory foundation.

\section{THE INTERPRETATIVE-HISTORICAL FOUNDATIONS OF EDUCATION- AL RESEARCH}

What we understand by tradition is not merely a heritage of attitudes, beliefs, customs, cultural and artistic forms inherited from the past. Tradition also includes patterns of scientific and technological accomplishments, patterns of development in trade, commerce and industry, which are distinguishing marks of a society, and includes further the human benefits or conflicts to which such accomplishments and developments give rise. Hence to acknowledge our social nature as humans is also to acknowledge that we always stand within tradition. Very often indeed our 'philosophies' of education are founded on an inadequate or distorted acknowledgement of our standing within tradition, with the result that the conflicts in tradition itself give rise to conflicting educational ideologies. As soon as educational discourse becomes primarily characterised by continuing disputes between these ideologies, a primordial or original understanding of education becomes more difficult to establish and may even become threatened with obscurity. A radical acknowledgement of what it means to stand within tradition, however, allows us, for the first time, to bring within our grasp an understanding of education which contains no ideological programme. Hence we can characterise education as the fruitful interplay between the unfolding experience of an individual and the movements of tradition. On a wider scale, education can be characterised as the interplay between the self-understanding of a society, including its various sub-cultures, and the traditions it encounters in its daily experience. If it is objected that such a characterisation contains no explicit or recognisable educational aims it must at once be replied that the characterisation itself expresses an aim to be realised, namely the bringing about of a fruitful interplay. If more specific aims are sought, for example "the preparation of an individual for membership of society" [28], ideological elements begin to creep in, in the form of a 'hidden curriculum' or an explicit programme of indoctrination through which such 'preparation' takes place. To conceive of tradition, therefore, as something which must simply be passed on through education is precisely to overlook the nature and the educational importance of tradition itself.

These remarks require that the nature of the interplay suggested needs to be examined more closely now, together with an examination of what makes the interplay fruitful. Tradition itself, or indeed any particular aspect of it, is a field abundant with aims, ambitions, fulfillments and frustrations. This becomes clear on a moment's reflection whenever we encounter the development of man's accomplishments and failures, whether in science, literature, industry, politics or in his concern for fellow humans. Our daily experiences of competing and often conflicting claims for our energies, allegiances and aspirations, show equally clearly the unceasing penetration of our lives by tradition. Now any aspect of tradition can become a field of study for educational purposes. This is normally accomplished through the selection of material under clearly defined subject areas such as History, Chemistry, Mathematics, Sociology, Languages, Literature and so on, although interdisciplinary approaches, which suggest such titles as Social and Environmental Studies, Media Studies, Development Studies and so on, are recently gaining in importance. What is crucial in the selection and presentation of curriculum material however is that a genuine encounter with tradition is facilitated. In other words, it is crucial that pupils or students are addressed by something which is living, and which there- 
fore speaks to their own experiences. This is what is meant by bringing about an interplay, and as an educational task it describes the work of the teacher.

We are arguing therefore that a teacher understands his or her purposes in a properly educational light only when he or she gives primary importance to making pupils and students aware of the vital life of Mathematics, of Physics, of Literature etc. or, more simply, aware that what is being studied has something important, or potentially important to say to them. The alternative for the teacher is to take the view that so much syllabus material must be covered, so much knowledge must be instilled, to comply with examination or other requirements. There lurks continually in this latter approach the possibility that the student may master the material formally and give a creditable performance when required to do so, but that he or she will remain unmoved by, or even moved to a positive dislike of, the subjects taught in this way. This danger is highlighted in one of Dewey's remarks which argues as follows:

Perhaps one of the greatest pedagogical fallacies is the notion that a person learns only the particular thing he is studying at the time. Collateral learning in the way of formation of enduring attitudes, of likes and dislikes, may be and often is much more important than the spelling lesson or less in geography or history that is learned. [28]

The dimension of 'collateral learning' mentioned here by Dewey is the dimension of the student's experience which, as we previously saw, lies inwardly active beneath the surface of displayed behaviour. In order to bring about a fruitful interplay with any aspect of tradition it is precisely this experiental dimension which must be addressed, reached and most importantly, moved by the curriculum or, more particularly, by the teacher's understanding and presentation of the curriculum. If it is the teacher who must in practice attempt to make the interplay with aspects and movements of tradition a fruitful one, then the teacher needs to be assisted in this work by educational research, for the task to be accomplished is by no means a process of simple instruction, or didactic lecturing.

One of the major questions for educational research thus becomes that of discovering how a field of study or context selected from tradition can, through a teacher or other medium, be brought into a progressively fruitful dialogue with pupils or students. A further task becomes that of working out practical ways of achieving this purpose with pupils of different ages, social backgrounds, temperaments and abilities. In order to embark on this work in any successful measure educational research must first, as we previously illustrated, understand the historical-social context in which it operates or, in other words, must be clearly aware of how the researcher's own effective history always remains active and influential, and all the more powerfully so in any methodology which claims to have eliminated 'subjective bias'. This is to suggest that the person who engages in educational research must be trained not only in the conventional methodology of his or her own discipline, whether psychology, sociology, history, anthropology or philosophy, but must also be continually and critically conscious of the interpretative foundations of that discipline in the structure of understanding; or must have, in Gadamer's words, a "hermeneutically trained mind" [30].

In examining his data therefore, the educational researcher, as psychologist, anthropologist, sociologist, historian or philosopher, must recognise that he is being addressed by products of human experience-an experience which he understands in a different way than any mere organic process is understood. Hence, rather than simply impose his own methodological scheme on the data he must be prepared for the data to tell him something new, and to tell him in a challenging manner which may even break asunder the methodological classifications and categories designed to accommodate and process the data. In 


\section{Oxford Review of Education}

this way, just as the researcher must be sensitive to the historical influences in his own context of experience he must also be sensitive to the particular qualities and nuances of the human context he is attempting to understand. What Gadamer says of sensitivity in textual interpretation can equally be applied here if we take the researcher's data as the 'text' to be understood:

this kind of sensitivity involves neither 'neutrality' in the matter of the object nor the extinction of one's self, but the conscious assimilation of one's own foremeanings and prejudices. The important thing is to be aware of one's own bias, so that the text may present itself in all its newness and thus be able to assert its own truth against one's own fore-meanings. [3I]

From this it now becomes clearer that if, when attempting to understand anything, we remain unaware of the preconceptions and prejudices we bring with us from our previous experience: if we merely proceed with a naive faith in an established method, then our overlooked preconceptions and prejudices prevent us from understanding properly what we seek to understand because they constitute the fixed horizon beyond which we cannot effectively see. With the disciplined attempt to become aware of our prejudices on the other hand, we do not naively assume that our present understanding has a superior status over all previous understanding. Rather we begin to realise what it means to have a horizon: the shifting limits of our own context of experience become more visible to us together with an awareness that ours is never an independently fixed or isolated context but is continually being formed from the movements of tradition itself. Understanding, then, is the fusion of contexts which are different from one another (one's own and that which one is attempting to understand) but which both belong to the continuity of tradition.

It is of special importance that the understanding which takes place in educational, or indeed any research-as distinct from everyday understandings in social intercourseshould be an exemplary case of understanding. No real fusion occurs when the methodological context of the researcher attempts, albeit unwittingly, to dominate the context to be examined or, alternatively, where research itself becomes dominated by the dogmatic imperatives of an authoritarian tradition. The fusion is truly productive only when the awareness of historical prejudices in his own context enables the researcher to interpret and distinguish more clearly the prejudices which lie in tradition itself. Thus, through the circular interplay between the interpreter and tradition described earlier, the researcher questions tradition and is in turn questioned by tradition as his own questions begin to be answered. This in turn leads to a further questioning of tradition, and so the circle continues into a 'spiral' which enables the researcher to anticipate ever more productive encounters and to bring to light in the process findings and recommendations which can, if taken up and acted upon by teachers, colleges of education, educational institutions and providing agencies, and not least by other educational researchers, make human experience more richly educational for individuals and for communities more widely [32].

In the process just described no distinctions are drawn between different disciplines of educational research. This is deliberate as the argument which has been put forward includes in its scope all forms of legitimate enquiry into the human condition. The productive encounters with tradition to which we have just referred are equally possible for psychology, sociology, anthropology and philosophy as they are for history itself. What must, however, be borne in mind in order to achieve this productive encounter is the interpretative historical nature of human understanding, as it operates in these disciplines. In this way, educational research, adequately understood, can lead not only to real improvements in the efficiency of a particular educational system, but can also 
show how, on a wide scale, tradition itself can be brought to light in such a way that it does not dominate us, or seek merely our thoughtless acquiescence, but rather that it becomes genuinely thoughtworthy for us, that we become enabled to question it articulately and to ask for articulate answers.

The productive involvement with tradition which thus distinguishes education opens up new possibilities for human fulfillment or indeed for human suffering, and in this way tradition itself can become enriched or impoverished. Our success in this endeavour, that of enriching our research, our educational practice and our lives more generally, can be measured by the extent to which we can still extend to those who come after us, the promise of human fulfillment.

\section{NOTES AND REFERENCES}

[I] Nisbet, J. D. \& Entwistle, N. J. (1973) The psychologist's contribution to educational research, in: TAYLOR, W. (Ed.) Research Perspectives in Education, pp. II3I20 (London, Routledge \& Kegan Paul).

[2] Ibid., p. II3

[3] Ibid.

[4] Ibid.

[5] Ibid., pp. II3-II4

[6] For instance, other articles in the same book mention a distinction between empirical and non-empirical educational research but do not pursue the distinction itself as a theme to any conclusive extent. For instance Professor Brian Simon's article, 'Research in the history of education' (pp. I2I-I49), claims that "it would be mistaken to think that psychology are the only disciplines relevant to education, because they are the ones at present established as such among educational studies, besides history itself and philosophy in its 'spectatorial' role" (p. I42). Simon mentions the importance to education of developments in Government, politics and law and emphasises that they must not be neglected. There is an implicit suggestion in his remarks that empirical studies are guilty of such neglect but the suggestion is not made explicit or pursued. Also, an article by Professor Kjell Harnqvist on, 'The training and career structures of educational researchers' (pp. 45-87), quotes the United States National Academy of Education, in defining educational research as 'disciplined enquiry' which can follow 'formal procedures' or be 'free ranging and speculative'. Harnqvist argues that "defined in such a way educational research not only comprises empirical enquiry with quantitative techniques but also naturalistic observations, logical and philosophical analyses and historical studies" (p. 46). The 'not only' in his remarks alerts the reader that a distinction between empirical and non-empirical studies is being indirectly referred to here and that a plea is being entered for a comprehensive definition of educational research which would include both elements in the distinction.

[7] Nisbet \& ENTWistle, p. II4

[8] See for instance HARNQvisT, KJELL The training and career structures of educational researchers, Research Perspectives in Education, pp. 45-87.

[9] Dissertation Abstracts International: Section A, Humanities and Social Sciences (North America Section B, Sciences and Engineering (North America), published monthly by University Microfilms International, Ann Arbor Michigan: Section $C$, European Abstracts (covering arts and sciences), published quarterly by University Microfilms International, I 8 Bedford Row, London. 


\section{Oxford Review of Education}

[10] Encyclopaedia of Educational Research, edited by Robert L. Ebel, Victor H. Holl and Roger M. Bauer (published by Macmillan for The American Educational Research Association, fourth edition, 1969). See in particular the articles entitled 'Research in education' and 'Research methods', pp. II27-II5O and, by contrast, the editors' preface pp. V-VI.

[II] Richmond, W. Kenneth (1972) The Literature of Education, a Critical Bibliography 1945-1970, p. 13 (London, Methuen, USA, Barnes \& Noble).

[12] The distinctive features of Recurrent Education and 'Education Permanente' are outlined and discussed in the following documents, which form only a selection from the available literature:

(I) Haughton, V. \& Richardson, K. (Eds) (1974) Recurrent Education: a Plea for Lifelong Learning (London, Ward Lock and Association for Recurrent Education).

(2) OECD (1973) Recurrent Education: a strategy for lifelong learning (Paris, Centre for Educational Research and Innovation).

(3) Council of Europe Permanent Education: a Framework for Recurrent Education (Strasbourg, 1975) and Permanent Education: the Basis and Essentials (Strasbourg, 1976).

(4) Dave, R. H. (1976) Foundations of Lifelong Education (published for UNESCO Institute of Education by Pergamon Press).

[13] Boyd, W. \& KING, E. J. (1966) The History of Western Education, 8th edn, particularly chapters II, I2, I3 and I4 (London, Adam \& Charles Black).

[14] Greek and Roman education were, for the most part, concerned with the training for their particular kinds of states, of youth which did not belong to the slave class. In later times education was mainly confined to noblemen and churchmen, many of whom proceeded to become 'men of letters' after completing their formal tuition.

[I5] KING, E. J. (Ed.) (1974) Communist Education (London, Metheun).

[16] Coles, E. K. Townsend (1977) Adult Education in Developing Countries, 2nd edn (published for UNESCO by Pergamon Press).

[17] Plato, Meno, in The Dialogues of Plato, 4th Edn, Vol. I, pp. 277-285, translated by B. Jowett (Oxford, Clarendon Press). There is a clear parallel between the account of understanding given here and that given in the 'cave' allegory in Plato's 'Republic'. In the latter, the soul breaks through into the light from the darkness of this world (the cave) and gains an illumination of ultimate reality.

[18] Kant, I. (1968) The Critique of Pure Reason, p. 93, translated by N. Kemp-Smith (London, Macmillan).

[19] Ibid., pp. 67-9r.

[20] Ibid., pp. 320, 533

[22] HeIDEgGeR, M. (1973) Being and Time, pp. I82-I88, translated by J. Macquarrie \& E. Robinson (Oxford, Blackwell).

[22] Descartes, R. (1934) Collected Works, Vol. I, p. I52, translated by E. S. Haldane \& G. R. T. Ross (Cambridge University Press). Here Descartes answers his own question 'What am I?' as follows: "A thinking thing. What is that? One that doubts, understands, asserts, denies, is willing, is unwilling, which also imagines and feels." The addition of these attributes does not alter Descartes' conception of himself as a 'thing'.

[23] Heidegger, ibid., pp. I88-195.

[24] Even where structural and administrative changes born of the success of a revolution alter substantially the conditions in which life is experienced in any society, the 


\section{$A$ Critique of Educational Research}

earlier tradition is not thereby wiped out. This can be seen for instance from a study of life in the USSR where the nineteenth century masters of Russian literature still hold a central place in the curriculum, alongside twentieth century technology. The 'overthrow' of bourgeois traditions may often mean in reality the opening up of the more enriching aspects of these traditions to a much greater number of people.

[25] Gadamer, H. G. (I975) Truth and Method, translated by G. Barden \& J. Cumming (New York, Seabury Press). The German term is 'Wirkungsgeschichte' which is translated as 'effective history', p. 267 and following.

[26] Ibid. The origins, development and applications of this circular interplay of whole and parts, are treated in detail in Gadamer's book.

[27] The account of understanding given here, drawing on some of the more important insights of contemporary European philosophy (Heidegger, Gadamer), provides a strong philosophical foundation for the notion of the 'spiral' curriculum advocated by Jerome Bruner.

[28] Influential sociologists such as E. Durkheim and T. Parsons have viewed education in these more ideological terms, namely, preparation for the type of society in which one lives and for one's specific position in that society. Education carried out in accordance with this characterisation is precisely the negation of the encounter with tradition suggested in the third part of this essay.

[29] Dewey, J. (1975) Experience and Education, p. 45 (New York, Collier MacMillan).

[30] In a section of his book entitled 'Foundations of a theory of hermeneutical experience', Gadamer points out that a hermeneutically trained mind is one which, recognising the interpretative or 'hermeneutic' nature of understanding, recognises also the influence of effective history on all understanding. This recognition can never be an absolute one, i.e. can never become completely aware of effective history (p. 235 and following).

[3I] Ibid., p. 238.

[32] The 'illuminative' paradigm in educational research advocated in recent years by Malcolm Parlett and David Hamilton provides an example of how this 'spiral' might work in practice. A number of articles which examine the 'illuminative' approach are gathered together in a recent book entitled Beyond the Numbers Game: a reader in educational evaluation, edited by D. Hamilton, D. Jenkins, C. King, B. MacDonald and M. Parlett (London, MacMillan, 1977). 